\title{
Alimentação e codificação social. Mulheres, cozinha e estatuto*
}

Rosa Maria Perez ${ }^{* *}$

\section{Resumo}

Este artigo tem como base um trabalho etnográfico de longa duração realizado na Índia rural (Gujarate) com um grupo de mulheres Dalit (termo pelo qual são designados os "antigos" intocáveis da Índia) e, por extensão, mulheres de outros grupos sociais. Pretendo analisar a forma como a produção, distribuição e confecção de alimentos funcionam simultaneamente como formas de segregação feminina $e$ de afirmação de poder por parte das mulheres, sobretudo em situações ligadas à fecundidade.

Palavras-chave: Dalit, Gênero, Cadeia Alimentar, India.

* Recebido para publicação em 23 de julho de 2012, aceito em 10 de agosto de 2012.

** Antropóloga, Professora do Departamento de Antropologia do ISCTE-Instituto Universitário de Lisboa e Institute Chair Professor (Anthropology), Indian Institute of Technology (IIT) - Gandhinagar. rperez.perez@gmail.com

cadernos pagu (39), julho-dezembro de 2012:227-249. 
Mulheres, cozinha e estatuto

Food and Social Codification: Women, Cuisine and Status

\begin{abstract}
This article is grounded on a long-term fieldwork carried out in rural India (Gujarat) with a group of Dalit women (the term for which are designated the "old" untouchables of India) and, by extension, with women from other social groups. I intend to analyze how food production, distribution, and cooking operate both as a form of segregation and of women's assertion of power, particularly in situations related to fertility.
\end{abstract}

Key Words: Dalit, Gender, Food Codification, India. 
As foodways change, so does the culture

(Couniham 2004:186)

\section{Cozinhar o mundo. Alimentos e significação' ${ }^{1}$}

Num dos conjuntos de textos mais importantes da literatura clássica indiana, Brahmana ${ }^{2}$, encontramos a seguinte passagem:

Prajapati pensou: "Se eu adicionar isto, tal como é, à minha pessoa, vou tornar-me uma carcaça mortal, não liberta do mal. Posso, pois, cozinhá-lo com fogo". Ele cozinhou-o com fogo e transformou-o na alimentação da imortalidade. Efectivamente, a oferenda torna-se a alimentação da imortalidade quando é cozinhada com fogo. É por isso que se cozinham os tijolos com fogo. Desta forma, são tornados imortais (Satapatha Brahmana, 6.2.1.9). ${ }^{3}$

A ideia de "cozinhar o mundo", em sânscrito lokapati, foi objecto de controvérsia por parte dos analistas do hinduísmo clássico para os quais "cozinhar" e "o mundo" seriam termos contraditórios. Efectivamente, a ideia de uma divindade superior, Prajapati", o "Senhor das criaturas", se dedicar a uma tarefa tão

\footnotetext{
${ }^{1}$ Agradeço as sugestões e comentários do Luís Gomes, a quem, obviamente, é alheia a responsabilidade teórica deste texto.

2 Corpo de literatura em sânscrito, cujo objectivo principal é mostrar que a integridade de entidades divinas só pode ser mantida através dos rituais aos quais estão ligadas, rituais estes que definem os limites do seu domínio.

${ }^{3}$ Prajapati considered: 'If I add this, such as it is, to my being, I will become a mortal carcass unliberated from evil. May I therefore cook this with fire'. He cooked it with fire. He made it into the food of immortality. In truth, the offering becomes the food of immortality when one cooks it with fire. This is why one cooks the bricks with fire. In this way, one renders them immortal (Satapatha Brahmana, 6.2.1.9) [tradução da autora].

$4 \mathrm{O}$ deus criador, frequentemente referido na literatura védica (de Veda, "conhecimento", um corpo de textos clássicos hindus), em particular nos Brahmana e nos Upanishad, que o descrevem como o avô dos deuses e dos
} 
insignificante como a cozinha durante um processo cosmológico parecia muito pouco razoável. Por isso, em lugar de "cozinhar", alguns autores preferiram a ideia de "aperfeiçoar" ou "amadurecer" (ver Malamoud, 1996). ${ }^{5}$

Se nos deslocarmos para outros contextos, podemos identificar um procedimento semelhante: uma entidade superior criando, a partir do lume, o homem, os seres vivos, o próprio universo. Para aqueles familiarizados com as Mythologiques de Lévi-Strauss não é de modo nenhum estranho o tema da produção de cultura através de uma actividade culinária. É esse, de resto, para Lévi-Strauss, um dos processos privilegiados de passagem da natureza (o universo do cru) à cultura (o universo do cozinhado), mediada pelo fogo de cozinha. Assim, se o mito de referência que inaugura as Mythologiques, cujo primeiro volume tem o título significativo de Le Cru et le Cuit (Lévi-Strauss, 1964), nos apresenta um jaguar cosmológico da mitologia Bororo com o papel aparentemente episódico de preservar o fogo doméstico da chuva e da tempestade, entre os Gé o antropólogo atribui ao jaguar o papel eminentemente cultual de cozinhar os alimentos. Embora o léxico culinário varie de sociedade para sociedade e, por vezes, dentro da mesma sociedade, os modelos de cozinha revelam-se, como este antropólogo referiu a propósito dos indicadores totémicos, "bons para pensar" (id., 1962).

Independentemente da dimensão crucial dada por LéviStrauss ao código alimentar na sua obra, ele faz parte de uma longa genealogia de antropólogos cuja identificação téorica excede o espaço e o escopo deste texto. Todavia, vale a pena, , referir alguns investigadores cujo contributo se revela imprescindível para quem tenta reconhecer, no domínio da alimentação, significações culturais e codificações sociais mais amplas. Começaria por indicar os estudos pioneiros da

demónios. Mais tarde, veio a ser identificado com Brahma, o deus criador da trimurti hindu, embora fossem aparentemente diferenciados nos Brahmana.

5 Para o desenvolvimento deste tema, ver Perez, 2006. 
antropóloga Audrey Richards (1932 e 1939) ${ }^{6}$ que, a partir do seu trabalho de campo de longa duração sobre os Bemba da Zâmbia (na altura Rodésia do Norte) e mais tarde na África do Sul e no Transval, centralizado na vida quotidiana e na cultura alimentar, na nutrição (que a levou a uma pesquisa transdisciplinar) e nas práticas alimentares, inspirou uma cadeia ininterrupta de pensadores nas ciências sociais e humanas. ${ }^{7}$ A antropologia britânica deu, desde o seu início, relevo à forma como a preparação e o consumo de alimentos detinham significações sociais mais vastas que etnografias posteriores enfatizaram. Destaco Jack Goody que, com base na sua pesquisa na África ocidental, no norte do Gana, se interrogou por que motivo não se desenvolveu neste continente uma "alta" cozinha diferenciada, mesmo em sociedades com superioridade política que deixaram, contudo, o plano culinário impreciso ou pouco desenvolvido, por oposição à Eurásia. Eis o que o conduziu, através de um périplo do Egipto à China ${ }^{9}$, a concluir que as diferenças na produção, preparação e consumo de alimentos nestas sociedades remetem para diferenças nas suas estruturas sócio-económicas e nos modos

${ }^{6} \mathrm{O}$ arquivo do longo trabalho produzido por esta antropóloga (que passou grande parte da sua juventude na Índia, onde o pai pertencia ao Conselho do vice-rei), incluindo os seus diários de campo, está disponível na Biblioteca da London School of Economics, sob o título Catalogue of Richards Papers.

7 Para o desenvolvimento desta influência, ver Counihan e Caplan 1998.

8 Traduzo literalmente do inglês high por oposição a low, "baixo", adoptado por Goody.

9 Para uma história social mais recente da cozinha bem como da trajectória dos alimentos entre culturas, ver Civitello 2008. Cito-a: "A identidade - religiosa, nacional, étnica - está profundamente ligada à alimentação. Todos os grupos se consideram a si próprios especiais e excepcionais e usam os alimentos para o mostrar. A identidade francesa está ligada ao pão branco, enquanto os italianos do sul seleccionam o molho de tomate. Esta identificação pode também tomar a forma de uma negação, através dos alimentos que são excluídos: 'Nós não comemos aquilo. Eles [religião, país, grupo étnico] comem-no."' (Civitello 2008:XIV) 
de organização da produção e da comunicação (Goody, 1982). ${ }^{10}$ Esta pesquisa viria a ser consolidada posteriormente por este antropólogo na mesma linha de argumentação (id., 1998). Não me parece, porém, que a questão mais importante seja o entendimento da oposição entre uma cozinha mais elaborada (high) entre os europeus e os asiáticos e uma cozinha menos elaborada (low) entre os africanos - categorias que, por si só, essencializam as sociedades que recobrem; a questão que me parece mais importante é o modo como essas cozinhas, independentemente da sua elaboração (critério marcadamente subjectivo), estruturam a relação entre os membros das sociedades que as produzem. Deslocando, assim, o centro da observação da natureza da cozinha para a natureza das representações $e$ codificações culturais.

Para os objectivos específicos do meu texto, saliento Marcel Mauss que, no seu ensaio fundador sobre a reciprocidade, Essai sur le Don (1967), e o respectivo papel na construção e preservação de relações sociais, elegeu a alimentação como uma componente essencial da troca, a qual mantém os indivíduos permanentemente em dívida uns para com os outros e, por isso, comprometidos numa interacção positiva. Mais do que qualquer

\footnotetext{
${ }^{10}$ Não resisto a citá-lo, pela intemporalidade do final da sua nota: "Escolhi como tópico um tema que estava a merecer a atenção de uma diversidade de investigadores e de abordagens, a alimentação, principalmente a cozinhada mas também a crua. O tema articula-se com o contexto mais vasto da relação entre as economias da Europa e da Ásia, por um lado, e, por outro, a África, que tentei analisar anteriormente em termos de relações entre sistemas familiares e modos de produção, bem como entre culturas orais e escritas, isto é, em termos de modos de comunicação “(...) Actualmente, uma produção tão ampla nas humanidades e nas ciências sociais consiste num desnecessário obscurecimento que constitui muitas vezes uma forma de disfarçar problemas intelectuais em lugar de os esclarecer. A subtileza não é uma função da obscuridade" (Goody 1982:1; itálicos meus).
} 
outra substância são os alimentos que, para Mauss, estruturam a reciprocidade. ${ }^{11}$

Quando nos deslocamos para a Índia, umas das análises mais pertinentes de que dispomos foi proposta pela antropóloga britânica Mary Douglas, que sublinhou de forma sistemática a importância do papel social (distinto do nutritivo e do fisiológico) dos alimentos, cuja lógica classificatória está, segundo a autora, subjacente às proibições alimentares (Douglas, 1966). Embora a pesquisa de Mary Douglas tenha sido desenvolvida fundamentalmente em contexto africano, entre os Lélé do Kasai, uma comunidade matrilinear do então Congo belga, ela tem, como tentarei mostrar, especial adequação à Índia. Além disso, ao sugerir que os sistemas simbólicos estão centrados sobre noções de masculinidade e feminilidade inscritas no corpo, o trabalho de Mary Douglas pode ser lido como uma espécie de feminismo, apesar de não ter sido, tanto quanto sei, analisado desse ponto de vista.

Na última década, novos estudos têm sido produzidos, os quais atribuem à alimentação uma via preferencial para aceder a outras questões, como a própria teoria antropológica e métodos de investigação. Dou como exemplo, Sidney Mintz e Christine $\mathrm{Du}$ Bois, para os quais os estudos antropológicos sobre alimentação permitem iluminar processos sociais mais vastos, questões de natureza simbólica e a própria construção social da memória (Mintz, 2002).

Antes de progredir na minha argumentação gostaria de acentuar que a atenção dada pelos antropólogos ao código alimentar não inclui estudos regulares sobre a relação entre alimentação e género (excepção feita ao trabalho pioneiro de

${ }^{11}$ Gloria Raheja (1992) viria a aplicar esta tese à análise do sistema de castas a uma aldeia do norte da Índia, argumentando, contra a noção de uma organização linear e gradativa de estatutos proposta por Dumont (1966), que o sistema social indiano assentaria numa lógica de troca, através da qual as castas dominantes transferiam para as outras, e em particular para os intocáveis, a poluição. 
Counihan e Caplan (1998) e de um pequeno conjunto de investigadores). ${ }^{12}$ Seria necessário revisitar a literatura produzida para decantar esta articulação, muitas vezes residual mesmo em trabalhos que deram centralidade às práticas alimentares na análise de grupos sociais. Além disso, uma grande parte dos trabalhos produzidos sobre alimentação negligencia a componente etnográfica a favor dos arquivos ${ }^{13}$, desperdiçando, assim, o poder dos alimentos para a adstrição e negociação estatutária entre grupos e entre géneros. Eis o que me proponho tentar explorar tomando como contexto de referência o Gujarate rural, onde, a partir de um estudo etnográfico realizado entre castas "intocáveis", actualmente designadas por Dalit ${ }^{14}$ (ver, sobretudo, Perez, 2004), pude expandir a minha observação da relação entre alimentação e género para outros contextos da Índia, nos quais, apesar das variações decorrentes da crescente urbanização do país, é possível observar recorrências que enunciam modelos comuns no universo hindu.

\section{Casta, alimentação e estatuto}

Será um lugar-comum afirmar que, em qualquer sociedade, a alimentação é uma forma intrínseca de cultura. Como comer, onde comer, com quem comer e, acima de tudo, o que

\footnotetext{
${ }^{12}$ Ver, neste volume, particularmente a análise de Pollock, de Khan e de Counihan (2004). Counihan desenvolveu esta relação com base num trabalho de campo de longa duração em Florença.

${ }^{13}$ Recentemente, o plano etnográfico foi metodologicamente valorizado no volume editado por Cheung, Sidney C.H. e Tan Chee-Bangh (2007), numa perspectiva mais contemporânea que interroga a relação entre alimentação $e$ identidade cultural (os autores usam o termo "étnico" que prefiro não usar neste contexto) e a formação de fronteiras, consumo e distribuição global e a invenção local num contexto de crescente contacto entre culturas, não negligenciando as questões políticas da produção alimentar.

14 O termo significa "inclinado" e, por extensão, "esmagado" e, como tentei demonstrar, não me parece coincidir social e ritualmente com as práticas cobertas pela intocabilidade (ver, nomeadamente, Perez, 2004, Prefácio, e 2012).
} 
comer, são elementos essenciais de significação cultural e de atribuição de estatuto. Efectivamente, o comportamento alimentar distingue posicionamentos sociais, género, afiliação religiosa, estado de vida.

A Índia permite-nos avaliar a eficácia da lógica alimentar na atribuição e definição de pertenças sociais, uma vez que, tal como a sexualidade, o comportamento alimentar está rigorosamente codificado. Assim, os conselhos de casta ${ }^{15}$ estabelecem, a par das possibilidades $e$ das interdições sexuais, possibilidades $e$ interdições alimentares cujo objectivo último é assegurar que a troca se processe no interior da casta, isto é, que ela seja respectivamente endogâmica e endoalimentar. ${ }^{16}$ É importante pôr em relevo que a transgressão a estas interdições é severamente penalizada e tinha - tem ainda frequentemente - como consequência o ostracismo social do/a(s) transgressor/a(s). A correspondência entre o plano alimentar e o sexual pode ser surpreendida nas cosmogonias de castas de baixo estatuto que justificam a sua desvalorização social com base em transgressões, sexuais mas mais frequentemente alimentares, cometidas, quase sempre inadvertidamente, por um antepassado da casta.

Desde os mais antigos textos religiosos do hinduísmo que podemos observar a centralidade do consumo de alimentos, quer ao nível ritual quer quotidiano. A cozinha dos homens e a cozinha dos deuses estão igualmente codificadas $e$ ambas obedecem à lógica da pureza e impureza ritual, detendo ambas um complexo

${ }^{15}$ No Gujarate rural, tal como noutros contextos da Índia, o conselho de casta é geralmente designado por panch, "cinco", por tradicionalmente ser constituído por cinco elementos. O conselho de aldeia e de unidades administrativas de maior dimensão - como o taluka, um conjunto de aldeias - é o panchayat, por também ser originalmente composto por cinco indivíduos.

${ }^{16}$ Uso o neologismo para sublinhar o paralelismo existente entre os dois registros. Não é este o lugar para analisar a resiliência da troca sexual e alimentar no sistema de castas. Diria que, embora a primeira seja mais consistentemente preservada, a segunda emerge como um poderoso mecanismo de definição estatutária: aceitar ou recusar alimentos indica o posicionamento relativo - $e$ relacional - entre pessoas de castas diferentes. 
simbolismo manifesto nomeadamente nas precauções que cercam os alimentos $e$ o acto alimentar.

Os alimentos, divididos em duas categorias principais, pakka e kacca $^{17}$, são extremamente sensíveis à poluição ritual - cujo resultado é jutha, um alimento impróprio - e, à excepção da troca sexual, não há outra situação em que um indivíduo esteja mais exposto à poluição do que no acto de comer. Para ser mais precisa, é nos alimentos que consumimos que a oposição entre pureza e impureza emerge mais claramente (Perez, 2006:82).

Estes alimentos traçam os limites entre castas por meio de dois indicadores: a sua natureza (sendo o vegetarianismo a prática alimentar mais valorizada) e a sua aceitação/rejeição. Na verdade, a troca alimentar é um dos mais eficazes instrumentos de que o hinduísmo dispõe para se apreender a pertença social de um indivíduo e os limiares da sua casta. Como veremos, ela constitui também um meio fecundo de se aceder às relações de género.

Como indiquei recentemente (Perez, 2012), as duas grandes linhas explicativas para o sistema de castas foram construídas quase em espelho, a primeira atribuindo à casta a essência da Índia, numa fiada teórica posterior a Dumont (1966); a segunda, pelo contrário, concebendo a casta como uma criação do raj britânico para controlar uma complexa diversidade social $e$ religiosa de outra forma ingovernável - tendo esta perspectiva sido desenvolvida pelos principais analistas dos estudos pós-coloniais (ver entre outros, Inden, 1990; Ludden, 1996; Bailey, 1995; Dirks 2001).

Tenho vindo a sugerir o carácter excessivo destas duas propostas (ver Perez, 1997, 2004) e, nomeadamente, a ausência

\footnotetext{
${ }^{17}$ Pakka é o conjunto de alimentos perfeitos porque cozinhados com ghee, manteiga clarificada e um dos produtos purificadores da vaca, por oposição a kacca, o conjunto de alimentos cozinhados com água. Ambas participam, no entanto, da identidade de quem cozinhou, por isso, os alimentos crus são privilegiados na troca alimentar.
} 
substantiva de observação etnográfica da última. ${ }^{18}$ É oportuno lembrar Appadurai quando afirma que o conceito de hierarquia de castas satisfaz a necessidade dos estudiosos ocidentais de uma imagem única e forte que possa dar inteligibilidade a uma sociedade não ocidental (Appadurai, 1986) - premissa cuja aplicação não pode, evidentemente, ser restringida ao domínio indiano. Ora, as práticas alimentares são indicadores privilegiados de hierarquia e de estratificação social. Pelos alimentos que se aceita e que se rejeita passa uma complexa rede de significações que nos permitem aceder claramente à identidade social de um indivíduo. ${ }^{19}$

Não é este o contexto para explorar, num universo mais lato, a forma como a recusa e a aceitação de cozinhas diferentes está culturalmente carregada de sentidos. Efectivamente, na troca alimentar ou na sua recusa podemos reconhecer formas de aceitação e de rejeição da diferença; aí, onde menos esperamos,

${ }^{18}$ Seria interessante, a este título, e seguindo a via das representações alimentares, sugerir uma literatura de viagens sobre a Índia que, desde muito precocemente, associa alimentação e casta, numa verdadeira arqueologia do pensamento antropológico sobre o contexto indiano. Cito, como exemplo, Abbé Carré: "Estes Hindus não são tão austeros e rigorosos na sua religião como são os do Indostão. Os últimos podem ser considerados 'reformados' porque observam a sua lei e os costumes antigos - não comendo nem carne, nem peixe, nem nada que tenha tido má vida, nem mesmo qualquer alimento que tenha sido tocado por pessoas de outra casta. Fazem um alarido e realizam centenas de ritos para purificar o que quer que queiram comer, antes de o cozinharem." (Abbé Carré, 1990, vol. II:592-3)

${ }^{19}$ Eis o que Elizabeth Collingham (2006:XIV) deixou claro no seu último livro, dedicado à história da alimentação na Índia: "A relação dos britânicos com a alimentação indiana continua a captar a minha imaginação e, enquanto fazia pesquisa para este livro, fiquei surpreendida ao descobrir que o chá foi provavelmente o mais importante produto alimentar que os britânicos legaram à Índia. (...) Traço as suas raízes culinárias [de pratos indianos], a sua descoberta, a sua invenção por Europeus e os diferentes processos através dos quais viajaram para a Grã-Bretanha e para o resto do mundo". Para um interessante estudo da cozinha colonial, e ainda a propósito do caril, ver Leong-Salubir (2011:40) para quem o caril constitui "o mais importante prato para definir a história culinária do colonialsismo britânico." 
espreitam gradações de racismo cultural evidenciadas naquilo que em algumas sociedades se configura como um mero gosto alimentar.

Além disso, na Índia como noutros espaços, os alimentos edíveis e não edíveis marcam os limites de categorias sociais, contextos e práticas rituais, distinguem indivíduos e grupos. Estas classificações não são aleatórias e remetem para representações precisas e socialmente determinadas.

Aqui chegados, vale a pena lembrar de novo Appadurai, desta vez a propósito de um texto a que chamou "Gastro-politics in Hindu South Asia" e onde analisa as propriedades semióticas dos alimentos como uma forma de "gastro-política". Segundo este antropólogo, na Ásia do Sul, onde as representações alimentares remetem para um complexo conjunto de propostas sociais, a alimentação serve duas funções semióticas diametralmente opostas: pode homogeneizar ou heterogeneizar os indivíduos que a transaccionam (Appadurai, 1981). ${ }^{20}$

$\mathrm{Na}$ mesma linha de pensamento, tentarei mostrar como a alimentação opera no plano das relações de género.

\section{Mulheres, alimentos e estatuto}

O controlo da produção dos alimentos está eminentemente nas mãos dos homens, independentemente da participação, por vezes quase análoga, das mulheres nas actividades agrícolas -

\footnotetext{
${ }^{20}$ Regresso a Civitello (2008:XIV), numa passagem expressiva: "A alimentação pode constituir uma arma política. Depois da oposição francesa à invasão do Iraque pelos Estados Unidos da América, alguns americanos recusaram-se a comer batatas fritas francesas [French fries], mas não tiveram qualquer problema com as batatas fritas da Liberdade [Freedom fries], o mesmo alimento, só que com outro nome. Ao longo da história, as pessoas de um determinado país usaram a alimentação como uma forma - geralmente não complementar - de se referirem a pessoas de outro país. Quando os britânicos descobriram que as limas eram uma cura para a carência de vitamina $\mathrm{C}$, o escorbuto, tornaram-se 'Limeys'. Os franceses comiam pernas de rã, por isso, eram chamados 'Rãs'. O amor dos alemães pelas couves etiquetou-os como 'Krauts'."
} 
participação que se verifica sobretudo em grupos sem poder económico e que, associada às actividades domésticas, manifesta uma assimétrica distribuição do trabalho por género. ${ }^{21}$ Deste ponto de vista, o controlo de um recurso fundamental, a produção dos alimentos, dá maior poder aos homens, embora, como explicitarei, esse poder não seja estável, como nos é possível verificar quando nos deslocamos para o domínio das classificações simbólicas do poder. É neste plano que, como também tentarei evidenciar, pode ser revertida a hierarquia de gênero. ${ }^{22}$

Os homens comem primeiro e está-lhes reservada uma parte substancial dos alimentos preparados para a família, excepção feita, como veremos de seguida, à mulher grávida ou à mulher possuída por um bhut, um espírito malévolo. A distribuição de alimentos por género assinala, desta forma, uma hierarquia que é observada mesmo em circunstâncias de grande escassez. Foi o que pude verificar durante a grande seca que afectou o Gujarate e o estado vizinho do Rajasthan nos finais dos anos de 1980 e cujas proporções levaram o governo a considerá-la uma calamidade nacional. Nessa altura, respeitada a hierarquia de género na distribuição alimentar, era reservada às mulheres uma porção insuficiente de alimentos, insuficiência essa que era complementada, facto não despiciendo, pelo consumo de alimentos não edíveis. Deste modo, os rotli, espécie de pão, nesse tempo dominante na cozinha dada a ausência de água para a produção de arroz, serviam de base a diferentes formas de pratos

\footnotetext{
${ }^{21}$ A complementaridade de género através da produção de alimentos foi identificada para outros contextos (ver Khan, 1986, para o caso, muito interessante, do taro entre os Papuas da Nova Guiné; ver Pollock, 1998, para os Culina da Amazónia ocidental), estando tendencialmente adscritos às mulheres os produtos hortícolas $e$ aos homens a carne, facto que não se verifica necessariamente no universo rural gujarati. No entanto, todas as actividades associadas ao trabalho directo com o gado são realizadas por homens.

22 Para Goody, a questão era bem menos ambígua: as hierarquias de classe, casta, raça e género são mantidas, em larga medida, pelo controlo e acesso diferenciado aos alimentos (Goody, 1982).
} 
cozinhados com massala ${ }^{23}$, especiariais, a partir de folhas tenras de árvores ou de rebentos que, noutras situações, eram impróprios para a alimentação humana.

Esta situação extrema que, na altura observei a partir da base do sistema, entre os Vankar, uma casta de tecelóes intocáveis, leva-me a discordar da ideia, defendida por alguns antropólogos que trabalharam sobre a Índia, de que a mulher consome os restos alimentares do marido. Efectivamente, mesmo nos casos de mulheres que amamentavam e cuja exiguidade de nutrição afectava, por vezes irremediavelmente, a saúde se não mesmo subsistência dos filhos, os restos alimentares do marido não eram partilhados. É que a poluição ameaça, como referi, todos os alimentos e, particularmente, os restos alimentares. ${ }^{24}$ Esses restos não são apenas os restos de uma coisa, são os restos de uma pessoa cuja identidade partilharam. Por isso, idealmente, os únicos restos partilhados são os de um filho pela mãe e, mesmo neste caso, enquanto ela amamenta a criança, mantendo, pois, com ela laços de continuidade que serão conservados ao longo da vida. ${ }^{25}$

${ }^{23} \mathrm{O}$ termo genérico caril, usado grosseiramente para designar a cozinha indiana, e que foi, de facto, uma criação produzida durante o raj britânico para minimizar a exuberância extrema das massala e as adaptar ao paladar ocidental, recobre uma cozinha diversificada que, além disso, nos permite fazer o rastreio das diferentes presenças civilizacionais na Índia, nomeadamente a mogol (para um interessante estudo desta diversidade, ver Collingham, 2006).

${ }^{24}$ Será que devemos detectar aqui uma contradição? Somente se prescindirmos de avaliar os efeitos que a lógica da poluição tem no plano do consumo alimentar. Por isso, se um homem tiver que interromper a refeição, o seu thali, prato metálico, é esvaziado por os alimentos que ele continha se tornarem impróprios para consumo, tendo-se tornado jutha.

${ }^{25}$ Lembro que o estádio máximo dessa continuidade ocorre, aqui como noutras sociedades, no parto, altura em que a mulher é portadora de uma poluição extrema, apenas comparável à da menstruação e da morte, e em que, por isso, lhe está vedada a proximidade com a cozinha e a confecção de alimentos até terminar o período de reclusão e subsequente purificação, que assinala o seu regresso à actividade culinária. 
Produção e distribuição de alimentos evidenciam, deste modo, uma hierarquia de género cujo topo é ocupado pelos homens e que eles usam, efectivamente, como mensagens de poder.

É mais complexo e mais carregado de significações o plano da confecção alimentar. É a mulher quem cozinha e nas famílias extensas a cozinheira preferencial é a sogra, seguida, na sua ausência, pela nora mais velha. Dois elementos devem ser aqui destacados: por um lado, a gestão da cozinha e a confecção de alimentos como um indicador de poder estabelecendo ele, por sua vez, uma hierarquia no interior do mesmo género; por outro lado, devemos notar a distância que, em princípio, as mulheres mais velhas têm relativamente à poluição menstrual. Por este motivo, a sogra, teoricamente mais próxima da menopausa ou já para lá dela, não é afectada por um dos maiores factores de poluição: a menstruação. Na verdade, a mulher menstruada é mantida em reclusão - ou, se o espaço da casa for insuficiente, deve permanecer o mais longe possível da cozinha - uma vez que o seu toque poluiria irreversivelmente os alimentos e, decorrentemente, a família.

Sugeri noutra altura que, pela via da poluição, mulheres $e$ intocáveis fazem sistema entre si (Perez, 2006b). Sugeri também, anteriormente, que, por via da poluição feminina na menstruação e no parto, alturas em que, como os intocáveis, são segregadas da família e da casta, excluídas de qualquer participação ritual $e$ adscritas a uma maior ou menor segregação ${ }^{26}$, a intocabilidade atravessa todo o sistema (Perez, 2004). Desta vez, pela ligação entre alimentos e género, gostaria de insinuar que aquilo que é

\footnotetext{
${ }^{26}$ Este período está, em princípio, intrinsecamente ligado ao estatuto da casta, dito de outro modo, quanto mais elevado ele for, maior é o período de reclusão feminina. Esta asserção, aceite quase consensualmente pelos antropólogos, negligencia o conhecimento de castas da base do sistema social as quais, como pude verificar entre os Vankar, impõem às suas mulheres períodos de reclusão iguais se não superiores aos observados por castas socialmente mais valorizadas (Perez, 2004).
} 
aparentemente concebido como ausência de poder corresponde, de facto, a um extremo poder: a capacidade de poluir, isto é, de destruir a alimentação dos homens pelas mulheres. Este poder é partilhado pelos intocáveis / Dalit, embora, num caso como no outro, ele seja exercido com parcimónia - embora não desconhecido, como me afirmaram mulheres e intocáveis. ${ }^{27}$

A alimentação social por excelência é manifesta na hospitalidade, uma verdadeira instituição hindu. Ao hóspede é devido o tratamento dado a um deus e esse tratamento passa pela dádiva de alimentos, na Índia, divididos em três categorias: sólidos, líquidos e o fumo, o último eminentemente masculino. É interessante verificar que as mulheres manifestaram-me, em situações de grande cumplicidade, o poder que detinham pelo seu acesso privilegiado aos alimentos da dádiva através de pequenos "lapsos", como não lavarem as mãos antes de servirem chá a um convidado, ou tocarem no chá depositado nos pequenos pires em que ele era oferecido.

Pelos alimentos e pelo corpo das mulheres passam, portanto, duas vias de poluição e a capacidade, embora suspensa, de, por meio delas, agirem sobre os homens, os da família e os do grupo social a que pertencem - no primeiro caso enquanto receptoras no segundo enquanto emissoras de poluição. ${ }^{28}$ Num

\footnotetext{
${ }^{27}$ Como referi em tempos, os Vankar, apesar de conscientes do poder detido através da sua poluição ritual, inibiam-se de o exercer com receio de retaliações pelas castas de que dependiam em termos de mercado de trabalho (Perez, 2004). As mulheres, Vankar e de outras castas, assinalaram também o poder de destruir a alimentação dos maridos em situações de, nomeadamente, violência doméstica - exercício do qual nunca tive, todavia, conhecimento.

${ }^{28}$ Parece-me importante mencionar, a este propósito, o percurso de Elizabeth Collingham, do corpo á alimentação e que a autora sintetiza nos seguintes termos: "... o meu primeiro livro foi sobre o corpo britânico na Índia. Ele traçou o processo de mudança através do qual os britânicos controlaram, disciplinaram e apresentaram os seus corpos à medida que a sua posição na Índia passava do comércio ao controlo e ao imperialismo. Parte deste processo foi a sua rejeição dos caris indianos a favor de salmão em lata e ervilhas em frasco" (Collingham, 2006:XIII). Como Collingham (2002) demonstrou no seu primeiro livro, este
} 
caso como no outro, há o perigo de contaminação pelas substâncias mais poluentes para o hinduísmo: as secreções (saliva, sémen, suor) e, de uma forma geral, todas as matérias que saem do corpo humano (cabelos, unhas, etc.) e cuja remoção é feita por intocáveis ou por outras castas de baixo estatuto.

Constituirá uma evidência afirmar que, na Índia como noutros contextos, uma determinada categoria alimentar pode servir de metáfora a uma determinada categoria sexual e inversamente - um facto que diferentes culturas expressam desde logo no plano da linguagem, usando a terminologia alimentar para as diferentes fases do acto sexual. ${ }^{29} \mathrm{Na}$ Índia, esta relação não é apenas explícita, ela é, como vimos, eficazmente operatória quer na definição de identidades de género, quer, como também vimos, e mais generalizadamente, na adscrição de estatutos.

\section{A cozinha das deusas. Mulheres, alimentação e poder}

Na Índia, como noutros contextos, os alimentos são mediadores singulares de comunicação entre os homens e os deuses. ${ }^{30}$

Para o hinduísmo, o consumo alimentar não estratifica apenas os homens. Os deuses são eles próprios hierarquizados de acordo com os alimentos que recebem dos sue devotos. Assim, os deuses de castas superiores são sempre vegetarianos $e$ os frutos que lhe são consagrados no puja, a devoção hindu, são

paralelismo pode ser levado mais longe: quando o raj impôs aos seus funcionários na Índia um rigoroso controlo do corpo e a rejeição dos corpos nativos, impôs também uma alimentação metropolitana. Em ambos os casos, tratava-se de impedir que os colonizadores fossem seduzidos por um duplo perigo, potencializador da desestruturação do poder: sexo e alimentos (id., 2001).

${ }^{29}$ A antropóloga Ann Meigs abriu com o seu trabalho pioneiro realizado nas terras altas da Nova Guiné um interessante dossier etnográfico - infelizmente escasso - sobre a relação entre alimentos e identidade sexual (Meigs, 1984).

${ }^{30}$ Para o domínio grego, ver o interessante trabalho de Detienne e Vernant 1989. 
distribuídos sob a forma de prasad ${ }^{31}$ aos devotos. Em teoria, pelo contrário, os deuses de castas mais baixas querem alimentos animais para o seu culto. A minha observação etnográfica no Gujarate e em Goa, não me permite corroborar esta premissa. Há, todavia, uma divindade "carnívora", que exige o sacrifício animal no seu culto anual ou em circunstâncias de crise, social ou cósmica: a deusa, Devi ${ }^{32}$, nas suas diferentes formas. A exigência alimentar da deusa deve ser satisfeita sob pena de se manifestar o seu lado vingativo, parte da sua natureza ambivalente representada, no pólo oposto, pela sua vertente protectora, maternal, como indica o sufixo -ma ou - mata, "mãe", acrescentado ao seu nome.

A rapacidade da deusa encontra paralelismo entre duas categorias de mulheres. A situação mais relevante para o meu argumento é a das grávidas, a quem nenhum alimento pode ser negado, mesmo em situações em que o seu apetite insaciável ameace a subsistência da família. Mulheres e deusas partilham um componente que constitui também o princípio feminino de Shiva: shakti, o poder ligado à fertilidade. Este apetite excessivo e potencialmente ameaçador do equilíbrio familiar e social é manifestado por outras mulheres: as que foram possuídas por um espírito malévolo, genericamente bhut, sendo particularmente perigosos os espíritos de mulheres que morreram durante a gravidez e o parto. Nestas circunstâncias, manifestam um comportamento excessivo e inversor das práticas quotidianas $e$ comem desmesuradamente, até que os Raval, os ritualistas da deusa, consigam remover o espírito que as possuiu.

No Gujarate, como noutros estados da Índia, há grupos ou castas especializadas na mediação respectivamente entre a deusa

\footnotetext{
31 "Bondade, graça; dádiva dos deuses"; a porção de uma oferenda consagrada que é devolvida aos devotos, geralmente sob a forma de alimentos que são partilhados por eles.

${ }^{32}$ A deusa da tradição Shakta, isto é, o culto do princípio feminino, incarnado em muitas divindades femininas, as mais proeminentes das quais são Durga e Kali.
} 
e os homens $e$ entre as mulheres e os espíritos. Nas redes de aldeias que conheço essa casta é a dos Raval (ver Perez, 2004), pastores de gado e transportadores de pessoas e bens em carros de camelos, e os mediadores são sempre homens, contrariamente ao que alguns antropólogos observaram noutros lugares do país, em que são mulheres as ritualistas das deusas. Foi, nomeadamente a ocorrência estudada por Kinsley no Sul da Índia, onde Matangi, uma mulher de uma casta de Dalits, entra, tal, como os Raval do Gujarate, em transe durante o qual exprime os desejos alimentares da deusa. Interessantemente, consome bebidas intoxicantes (tal como os Raval), cospe nos que participam no ritual, usa uma linguagem obscena ao mesmo tempo que dança alucinadamente e empurra as pessoas que a cercam com o traseiro (Kinsley, 1986). Devemos reter o facto, sugerido por Kinsley, de que no ritual da deusa assistimos a uma inversão da ordem social quotidiana, já que o comportamento transgressor de Matangi, em circunstâncias normais extremamente poluente, se torna purificador. Por isso, em lugar de evitarem a sua saliva e os seus insultos, indivíduos de diferentes castas vão ao seu encontro para serem objectos do abuso de Matangi (idem). ${ }^{33}$ Ora, também no ritual de Bahavani-mata, a deusa da aldeia em que fiz trabalho de campo, membros de castas de estatuto mais elevado vinham assistir aos rituais da deusa, que ocorria num espaço onde em circunstâncias normais não entravam, espaço esse que, neste ritual, se encontrava especialmente poluído pelo sacrifício de uma cabra (animal ligado à fecundidade em muitos

\footnotetext{
${ }^{33}$ Cuniham e Caplan (2005) referem que, no ritual católico em que só sacerdotes masculinos podem realizar o ritual de transubstanciação em que o pão e o vinho são convertidos, respectivamente, no corpo e sangue de Cristo, "Os homens santos medievais subverteram por vezes a totalidade do controlo masculino ao recusarem-se a não comer nada senão a hóstia consagrada, desafiando a legitimidade de alguns padres ao vomitarem a hóstia e, deste modo, declarandoa não consagrada, e ao exsudarem alimentos milagrosos dos seus próprios corpos." (id.ib.:5).
} 
lugares da Índia) e posterior consumo da carne do animal morto pelos Raval (ver Perez, 2004).

Dos elementos acima apresentados, podemos retirar duas conclusões principais: em primeiro lugar, a inversão do comportamento quotidiano das mulheres, a quem está reservada uma maior escassez de alimentos, no interior de uma hierarquia de género favorável aos homens. Em segundo lugar, a constatação que esta inversão está ligada à fecundidade feminina e que, nesta medida, as associa à deusa - além de as aproximar, como vimos, de outras mulheres retiradas também elas, desta vez pela possessão, das práticas alimentares comuns.

Esta inversão é afirmada (ou deverei dizer confirmada?) uma vez por ano no ritual de Sitala, a deusa da varíola. Nesse dia, as mulheres não cozinham, demitindo-se, assim, de uma das suas principais funções: a confecção da alimentação da família. Reúnem-se num lugar separado do espaço social e consomem juntas os alimentos cozinhados na véspera, frios. Para alguns autores, o consumo dos alimentos frios no ritual de Sitala decorre do facto de a deusa ser extremamente "quente". À luz dos elementos etnográficos que apresentei, pergunto-me se não deveremos dar outra inteligibilidade a este consumo: tal como no ritual da Devi, assistimos a uma inversão dos comportamentos quotidianos: as mulheres soltam os cabelos, situação impensável no dia-a-dia, e podem ter outras condutas contrárias à ortodoxia imposta à pativrata, a mulher submissa e fiel ao marido.

$\mathrm{Na}$ escala oposta do espectro está a ausência de ingestão de alimentos: o jejum.

$\mathrm{O}$ jejum, preferencialmente realizado às sextas-feiras, tem como objectivo o cumprimento do dharma das mulheres casadas, patrivata dharma, isto é, manter a vida dos maridos. Às mulheres que sobreviveram ao marido está reservado um futuro indesejável: serão permanentemente inauspiciosas e, por isso, excluídas de todos os rituais e do puja, sendo que o ritual mais auspicioso é precisamente aquele que se destina a assegurar a fecundidade, da família e do grupo, o casamento. 
Fast and feast, para pedir de empréstimo o título de um romance da escritora indiana Anita Desai, marcam assim as possibilidades das relações de género por via dos alimentos: assimetrias, hierarquia e a sua inversão, reversibilidade de papéis e de estatutos.

Abre-se, pois, um percurso pesado de significações e ainda muito pouco percorrido: identificar nas práticas e nos códigos alimentares, e através de observações etnográficas sistemáticas, concepções de género mais vastas e mais subterrâneas.

\section{Referências bibliográficas}

ABBÉ CARRÉ. The Travels of the Abbe Carré in India and in the New East, 1672-1674, vol. II. Nova Delhi, Asian Educational Services, 1990.

APPADURAI, Arjun. Is Homo Hierarchicus? - A Review Essay. American Ethnologist, vol. 13, nº 4, 1986, pp.745-761.

. Gastro-ploitics in Hindu South Asia. American Ethnologist, vol. 8, n ${ }^{\circ} 3,1981$, pp.494-511.

BAyley, Susan. Caste, Society and Politics in India. From the Eighteenth Century to The Modern Age. Cambridge, Cambridge University Press, 1999.

CARLETTI, Francesco. La Cité dês Plaisirs. In : ChAndaigne, Michel. (org.) Goa 1510-1685. L'Inde portugaise, apostolique et commercial. Col. Mémoires, 41, Paris, Autrement, 1996, pp.160-180.

Cheung, Sidney C.H. e CheE-BAngh, Tan. (orgs.) Food and Foodways in Asia. Resource, Tradition and Cooking. Londres e Nova Iorque, Routledge, 2007.

Civitello, Linda. Cuisine and Culture. A History of Food and People. Nova Jérsia, John Willey and Sons, 2008.

Collingham, E. M. Imperial Bodies. The Physical Experience of the Raj, c. 1800-1947, Oxford, Polity Press, 2001.

Collingham, Lizzie. Curry. A tale of cooks and conquerors. Londres, Vintage Books, 2006. 
Mulheres, cozinha e estatuto

Counihan, Carole M. e Steven L. Caplan. (orgs.) Food and Gender. Identity and Power. Biblioteca electronic, Taylor and Francis, 2005.

Counihan, Carole M., Around the Tuscan Table. Food, family and gender in Twentieth-Century Florence. Nova Iorque e Londres, Routledge, 2004.

DÉTIENNE, Marcel and Jean-Pierre Vernant. The Cuisine of Sacrifice among The Greeks. Chicago, University of Chicago Press, 1989. [tradução de Paula Wissing]

DIRKS, Nicholas B. Castes of Mind. Colonialism and the Making of British India. Princeton, Princeton University Press, 2001.

Douglas, Mary. De la Souillure. Essay sur les notions de purité et de tabou. Paris, Editions de la Découverte, 1966.

Dumont, Louis. Homo Hierachicus. Essai sur le Système de Castes en Inde. Paris, Gallimard, 1966.

GoODY, Jack. Food and Love: a Cultural History of East and West, Londres e Nova Iorque, Verso, 1998.

- Cooking, Cuisine and Class: A Study in Comparative Sociology. Nova Iorque, Cambridge University Press, 1982.

INDEN, Ronald. Imagining India. Oxford, Basil Blackwell, 1992.

KINSLEY, David R. Hindu Goddesses. Delhi, Motilal Banarsidass e The University of California Press, 1986.

LeONG-SalubiR, Cecilia, Food Culture in Colonial Asia. A Taste of Empire. Londres e Nova Iorque, Routledge, 2011.

LÉVI-STRAuss, Claude. Le Cru et le Cuit. Paris, Plon, 1964. France, 1962.

. Le Totémisme Aujord'hui. Paris, Presse Universitaire de

LudDEN, David. Making India Hindu. Religion, Community and the Politics of Democracy in India. Delhi, Oxford University Press, 1996.

Malamoud, Charles. Cooking the World: Ritual and Thought in Ancient India. Delhi, Oxford University Press, 1996. 
MAUSS, Marcel. The Gift: Forms and Functions of Exchange in Archaic Societies. Nova Iorque, Norton, 1967 [1925].

MeIGS, Anna S. Food, Sex and Pollution: A New Guinea Religion. New Brunswick, Rutgers University Press, 1984.

MINTZ, S.W. e DU BoIS. C.M. The anthropology of food and eating. Annual Review of Anthropology 30, 2002, pp.99-119.

Perez, Rosa Maria. O Tulsi e a Cruz. Antropologia e Colonialismo em Goa. Lisboa, Círculo de Leitores/Temas e Debates, 2012.

Perez, Rosa Maria. Feeding Status: Food and Social Stratification in Goa. In: VARADARAJAN, Lotika. (org.) Indo-Portuguese Encounters. Jorneys in Science, Technology and Culture, vol. I. Nova Delhi, Indian National Science Academy, 2006a, pp.80-98.

. The limits of feminism. Women and untouchability in rural Gujarat. In: FruzzetTI, Lina e Tenhumen, Sirpa. (orgs.) Culture, power and agency. Gender in Indian ethnography. Kolkata, Stree, 2006b, pp.90-109.

. Kings and Untouchables. A Study of the Caste System in Western India. Delhi, Chronicle, Prefácio à edição inglesa, 2004.

. Hinduísmo e Cristianismo em Goa. In: PEREZ, Rosa Maria et alii (orgs.) Histórias de Goa. Lisboa, Instituto Português de Museus, 1997, pp.107-121.

Pollock, Nancy J. These Roots Remain: Food Habits in Islands of the Central And Eastern Pacific since Western Contact. Honolulu, Institute for Polynesian Studies, 1992.

RAHEJA, Gloria. The Poison in the Gift.Ritual, Prestation, and the Dominant Caste in an Indian Village. Chicago, University of Chicago Press, 1992.

RICHARDS, Audrey. Hunger and work in a savage tribe: a functional study of nutrition among the Southern Bantu. Londres, Routledge \& Kegan Paul, 1932.

WATSON, J.L. e CALDWELl, M.L. (orgs.) The Cultural Politics of Food and Eating: A Reader. Malden, Blackwell, 2005. 